\title{
Research on Performance Evaluation of Banking Listed Companies Based on RAROC Model
}

\author{
Xiaonan Ding ${ }^{1}$, Yanyu Feng ${ }^{2}$ and Guiying Liang ${ }^{3}$ \\ ${ }^{1}$ School of Wuhan University of Technology, Wuhan 430070, China; \\ ${ }^{2}$ School of Xinjiang Agriculture University, Xinjiang 830000, China; \\ ${ }^{3}$ School of Wuhan University of Technology, Wuhan 430070, China.
}

Keywords: RAROC; Performance-evaluation; Commercial-bank; Risk

Abstract. This paper studies how to evaluate the performance of commercial banks scientifically. RAROC model is used to analyze the financial data of 16 listed banks in China for 4 years. Then, this paper clarifies that RAROC (Risk-adjusted Capital Return Rate) is an appropriate index to evaluate the performance of commercial banks. The establishment and application of the index system with RAROC as the core will help to establish the restraint and incentive mechanism of commercial banks in China.

\section{Introduction}

With the gradual internationalization of China's financial industry, foreign banks have entered China and allowed to operate RMB business. Foreign Banks' strong capital strength, advanced management technology, and their rapid acquisition of domestic market resources have greatly impacted the development of China's financial industry. In order to maintain or even improve market share and gain relative competitive advantage in the highly competitive financial market, China's commercial Banks have been carrying out performance appraisal activities, testing the completion of business objectives and evaluating enterprise management ability.

The existing performance evaluation methods of commercial banks in China are mainly financial indicators evaluation method, balanced scorecard evaluation method, efficiency analysis method, economic value-added evaluation method. Although these indicators can reflect the performance level of enterprises to a certain extent, they do not take into account the risk.

This paper attempts to evaluate the performance of enterprises by RAROC index which takes into account the risk, so as to find out the shortcomings of operation and various factors affecting the performance. It provides theoretical support for improving and innovating the performance management mode and incentive mechanism of the company.

\section{Theoretical Analysis}

\subsection{Theoretical analysis of performance evaluation}

In terms of performance, domestic and foreign scholars have given many definitions. The commonly known ones are following: result performance theory, behavior performance theory and ability performance theory [1].In this paper, performance is defined as the operating results and operating efficiency of an enterprise during a certain period [2]. Operating results refer to the completion of the expected objectives of the enterprise, which measures the results; Operating efficiency refers to the work efficiency of employees in the process of achieving goals, and measures the process. Process and results are mutually complementary and indispensable. If only emphasizing process and paying no attention to result, formalism may arise. If only emphasizing result and paying no attention to process, some relatively important process factors may be neglected, and these factors may play a crucial catalytic role in improving enterprise performance.

For the listed companies in the banking industry, performance evaluation is aimed at developing ability, improving work and increasing bank value. 


\subsection{Feasibility analysis of bank performance evaluation based on RAROC}

Compared with other traditional performance evaluation methods, the key of RAROC is to accurately quantify the predictable future risk losses into current costs, adjust current income, and finally measure the size of the risk-adjusted income [3], so that the results are more in line with the actual situation.

RAROC model can accurately determine how much economic capital each business or product needs and how to calculate capital gains based on these needs. In addition, RAROC provides a consistent, reasonable and fair framework for measuring risk-adjusted returns, thus providing more practical information for managers to make risk/benefit trade-off. Compared with RORAA (Risk-adjusted Asset Return Rate) and RAROA (Risk-adjusted Asset Return Rate), RAROC (Risk-adjusted Capital Return) is closer to the bank's reserve withdrawal system, and can be used to evaluate the business activities of commercial banks at all levels, including various branches, business departments, or even specific to a certain bank employee.

\section{Empirical Research}

\subsection{Sample and data sources}

This paper takes 16 listed banks in China as the research object, and uses RAROC model to analyze their financial data for 4 years to draw conclusions. The model used data from the database of Tai'an and the China Securities Regulatory Commission website and accounting firm sites.

\subsection{RAROC model and index system}

RAROC, proposed by Banker Trust in the 1970s, refers to risk-adjusted capital gains. It is usually used to evaluate bank performance and measure the risk of bank credit portfolios. The basic model is as follows:

$$
\text { RAROC }=\frac{\text { Income }- \text { Capital costs }- \text { Operating costs }- \text { Expected loss }- \text { Taxes }}{\text { Economic capital }}
$$

According to the above equation, there are six main factors that affect the RAROC value:

Table 1 Related variables in the model

\begin{tabular}{c|c}
\hline Variable & Definition \\
\hline Income & The total cash flow of commercial banks during their daily operation \\
\hline Capital costs & The price paid by an enterprise to raise and use funds.[4] \\
\hline Operating costs & Various administrative expenses incurred in daily business activities \\
\hline Expected loss & Credit risk, operational risk, market risk and so on during management. \\
\hline Economic capital & Capital allocated for each loan to cover unexpected losses.[5] \\
\hline Taxes & Tax arising from daily business includes business tax and income tax. \\
\hline
\end{tabular}

This paper intends to calculate the five-year rate of return on risk-adjusted capital of 16 listed banks, calculate their mean and standard deviation, and evaluate the performance of commercial banks by economic capital combined with expected losses. RAROC value measures the rate of return after risk adjustment. The greater the RAROC value, the higher the enterprise performance level and the stronger the risk management and control ability; the lower the bank performance level, the weaker the risk management and control ability. RAROC mean and standard deviation reflect the overall situation of banks over the past 4 years. Economic capital and expected loss are two major factors affecting the RAROC value. According to the results of RAROC value and combined with the values of these two indicators, further analysis could be made from what aspects of the bank to improve the performance level of the bank, and then improve the value of the enterprise. Based on the actual situation, the RAROC model is directly simplified to the following equation:

$$
\text { RAROC }=\frac{\text { Net profit }- \text { Expected loss }}{\text { Economic capital }}
$$




\subsection{Empirical results analysis}

This paper calculates the RAROC value, RAROC mean value and RAROC standard deviation of the 16 listed banks in the past 4 years. The result is as follows:

Table 2 2013 2016related economic indicators of 16 Commercial Banks (unit: 1 million)

\begin{tabular}{|c|c|c|c|c|c|c|c|c|c|c|c|c|}
\hline Year & & 2013 & & & 2014 & & & 2015 & & & 2016 & \\
\hline L & 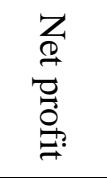 & 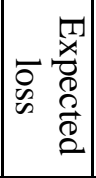 & 崩 & 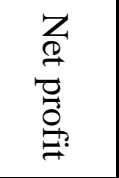 & 罟 & . & 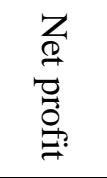 & 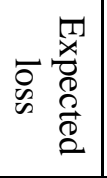 & 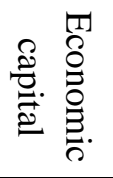 & 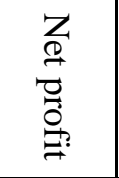 & 罟 & 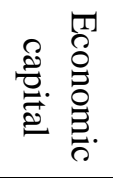 \\
\hline $\mathrm{BOC}$ & 14552 & 1 & 58100 & 16374 & 5 & 54253 & 17719 & 4171 & 72602 & 17942 & 61832 & 79695 \\
\hline CCB & 19360 & 24 & 72040 & 21512 & 203 & 54608 & 22824 & 4192 & 80571 & 22889 & 52404 & 90537 \\
\hline ICBC & 23869 & 46 & 73856 & 26296 & 4 & 83857 & 27628 & 2321 & 93181 & 27772 & 42859 & 102534 \\
\hline $\mathrm{ABC}$ & 14513 & 7 & 55490 & 16621 & 258 & 49295 & 17951 & 3559 & 70869 & 18077 & 33159 & 81591 \\
\hline CIB & 3492 & 220 & 11087 & 4151 & 42410 & 8303 & 4753 & 4974 & 13497 & 5065 & 1647 & 15506 \\
\hline BCM & 5847 & 3 & 21708 & 6246 & 429 & 27849 & 6603 & 2714 & 29613 & 6683 & 29116 & 32549 \\
\hline SPDB & 3431 & 43 & 11105 & 4120 & 11113 & 14664 & 4736 & 611 & 16542 & 5099 & 742 & 11105 \\
\hline PAB & 1351 & 479 & 7039 & 1523 & 33813 & 5312 & 1980 & 5138 & 8812 & 2186 & 965 & 10791 \\
\hline CMB & 3830 & 159 & 13029 & 4328 & 4835 & 10135 & 4556 & 4520 & 15207 & 4702 & 5053 & 17695 \\
\hline CMBC & 4527 & 70 & 15855 & 5174 & 3750 & 18459 & 5604 & 613 & 21223 & 5801 & 6136 & 24440 \\
\hline CNCB & 3138 & 14 & 13806 & 3971 & 4092 & 16334 & 4145 & 9291 & 18663 & 4174 & 10566 & 21708 \\
\hline CEB & 2362 & 3 & 7528 & 2675 & 533 & 10841 & 2892 & 1041 & 9988 & 2957 & 3827 & 13184 \\
\hline $\mathrm{HXB}$ & 1279 & 7 & 6940 & 1551 & 18402 & 5337 & 1802 & 1265 & 8085 & 1895 & 9701 & 9393 \\
\hline $\mathrm{BOB}$ & 1168 & 729 & 4842 & 1346 & 578 & 3426 & 1564 & 30 & 5814 & 1688 & 767 & 6755 \\
\hline NJCB & 404 & 6 & 1039 & 453 & 73 & 878 & 565 & 25 & 1454 & 706 & 157 & 2085 \\
\hline NBCB & 406 & 135 & 1424 & 484 & 72 & 1062 & 563 & 11 & 1782 & 656 & 34 & 2157 \\
\hline
\end{tabular}

Table 3 RAROC value of commercial banks

\begin{tabular}{c|c|c|c|c|c|c}
\hline Year & 2013 & 2014 & 2015 & 2016 & Mean & Standard deviation \\
\hline BOC & $25.04 \%$ & $30.17 \%$ & $18.66 \%$ & $-35.07 \%$ & $4.02 \%$ & $26.55 \%$ \\
\hline CCB & $26.84 \%$ & $39.02 \%$ & $23.13 \%$ & $-32.60 \%$ & $12.92 \%$ & $28.17 \%$ \\
\hline ICBC & $32.25 \%$ & $31.35 \%$ & $27.16 \%$ & $-14.71 \%$ & $19.70 \%$ & $20.95 \%$ \\
\hline ABC & $26.14 \%$ & $33.19 \%$ & $20.31 \%$ & $-18.48 \%$ & $13.27 \%$ & $20.12 \%$ \\
\hline CIB & $29.51 \%$ & $-40.76 \%$ & $-1.64 \%$ & $22.04 \%$ & $-99.58 \%$ & $31.53 \%$ \\
\hline BCM & $26.92 \%$ & $20.89 \%$ & $13.13 \%$ & $-28.92 \%$ & $-1.42 \%$ & $23.35 \%$ \\
\hline SPDB & $30.51 \%$ & $-47.69 \%$ & $24.93 \%$ & $9.24 \%$ & $-0.76 \%$ & $37.36 \%$ \\
\hline PAB & $12.38 \%$ & $-7.84 \%$ & $-35.84 \%$ & $11.32 \%$ & $-86.74 \%$ & $20.46 \%$ \\
\hline CMB & $28.17 \%$ & $-5.00 \%$ & $0.24 \%$ & $-1.98 \%$ & $8.07 \%$ & $15.41 \%$ \\
\hline CMBC & $28.11 \%$ & $7.71 \%$ & $23.52 \%$ & $-1.37 \%$ & $14.81 \%$ & $12.67 \%$ \\
\hline CNCB & $22.62 \%$ & $-0.74 \%$ & $-27.57 \%$ & $-29.44 \%$ & $-7.18 \%$ & $25.48 \%$ \\
\hline CEB & $31.33 \%$ & $19.76 \%$ & $18.54 \%$ & $-6.59 \%$ & $13.68 \%$ & $13.84 \%$ \\
\hline HXB & $18.33 \%$ & $-15.72 \%$ & $6.64 \%$ & $-8.11 \%$ & $-65.84 \%$ & $14.27 \%$ \\
\hline BOB & $9.05 \%$ & $22.42 \%$ & $26.38 \%$ & $13.63 \%$ & $14.90 \%$ & $8.55 \%$ \\
\hline NJCB & $38.24 \%$ & $43.25 \%$ & $37.12 \%$ & $26.37 \%$ & $31.78 \%$ & $7.95 \%$ \\
\hline NBCB & $19.07 \%$ & $38.81 \%$ & $30.96 \%$ & $28.86 \%$ & $28.43 \%$ & $7.22 \%$ \\
\hline
\end{tabular}


By observing the above table, we can find that:

Among the joint-stock commercial banks, the RAROC values of CMBC, CEB and CMB fluctuate less, and their risk management level is more prominent. Their earnings can offset their risks and their profits are more secure. The RAROC value of SPDB and CIB fluctuates greatly. The RAOC standard deviation of CIB in 4 years is $31.53 \%$. The fluctuation of SPDB is more intense, as high as $37.36 \%$. It is the most volatile of 16 commercial banks. As can be seen from the above table, the net profit of SPDB is far less than the expected loss, and its economic capital requirements are higher. The risk-adjusted return on capital of CIB was negative in three of its 4 years, and its expected losses in 2014 were the highest among the 16 banks. In addition, especially the RAROC value of CITIC Bank shows a decreasing trend, so we should find out the problem inside the enterprise and solve it in time.

The RAROC value of the city commercial banks in 4 years is all above 0, especially the Nanjing Bank. But if we only look at the net profit, we find that the Bank of Beijing has the strongest profitability, while its RAROC value is the lowest among the three banks. This also reflects the inadequate risk control ability of the Bank of Beijing and the inefficient allocation of economic capital.

Generally speaking, combined with Table 2 and Table 3, we can find that the economic capital allocation efficiency of listed commercial banks in China is not high, which needs to be further optimized. According to the five-year economic capital allocation and RAROC value changes of each bank, although some listed banks have relatively balanced capital allocation, their risk-adjusted return rate is relatively backward. Therefore, when banks allocate economic capital to all kinds of business, they should not only pay attention to the growth of efficiency, but also pay attention to the balance of business development. Only in this way can we achieve the optimal allocation of economic capital in the true sense.

\section{Conclusion}

According to the research on performance evaluation of Listed Companies in banking industry using RAROC method, we can draw the following conclusions:

(1) RAROC performance evaluation method links capital gains to investment risks. The level of RAROC indicators both depends on the level of business development and risk management and control capabilities of enterprises. Using RAROC as a performance evaluation index, the results measured are more in line with the actual situation than traditional performance evaluation methods.

(2) Through the analysis of RAROC indicators of commercial bank performance evaluation, we find that RAROC can not only be used for commercial bank performance evaluation or risk measurement, but also be used to allocate the capital of enterprises. Therefore, an enterprise can analyze how to allocate economic capital to achieve the desired objectives, with setting an expected RAROC value, in order to make full use of enterprise resources and maximize the benefits.

\section{Acknowledgment}

We would like to thank our thesis adviser for his valuable suggestions and comments.

\section{References}

[1]. Marcel Prokopczuk; Svetlozar T. Rachev; Gero Schindlmayr; Stefan Trueck. Quantifying risk in the electricity business: A RAROC-based approach[J].2007, 29(5)

[2]. Dan Borge. RAROC architect says banks can't ignore risk managers anymore[J].2013, 105(4)

[3]. Xu Li, "Application research of RAROC method in performance evaluation of bond trading business of commercial banks," [J]. Bonds, pp.44-48, November 2015. 
[4]. Li Xu, Cheng Lu, Zhu Zhu, and Dong Cao, "Construction of performance evaluation system of hierarchical commercial banks: a discussion on the performance evaluation method of financial enterprises," [J]. Finance and accounting newsletter, pp.42-43, May 2015.

[5]. Jiawan Gao, "Research on loan pricing of small enterprises based on RAROC," [D]. Zhejiang university, 2013.

[6]. Hong Li, "Empirical study on the risk management level of commercial banks-based on the RAROC model," [J]. Accounting communications, pp112-115, May 2017.

[7]. Jixian Huang, Liuliu Gu, "Comparative study on loan RAROC model pricing and bank pricing," [J]. Financial BBS, pp46-51, May 2014. 